\title{
The association among cytochrome P450 3A, progesterone receptor polymorphisms, plasma 17-alpha hydroxyprogesterone caproate concentrations, and spontaneous preterm birth
}

\author{
Martha L. Bustos, PhD; Steve N. Caritis, MD; Kathleen A. Jablonski, PhD; Uma M. Reddy, MD, MPH; \\ Yoram Sorokin, MD; Tracy Manuck, MD; Michael W. Varner, MD; Ronald J. Wapner, MD; Jay D. lams, MD; \\ Marshall W. Carpenter, MD; Alan M. Peaceman, MD; Brian M. Mercer, MD; Anthony Sciscione, DO; \\ Dwight J. Rouse, MD; Susan M. Ramin, MD; for the Eunice Kennedy Shriver National Institute of Child Health \\ and Human Development Maternal-Fetal Medicine Units Network
}

\begin{abstract}
BACKGROUND: Infants born $<37$ weeks' gestation are of public health concern since complications associated with preterm birth are the leading cause of mortality in children $<5$ years of age and a major cause of morbidity and lifelong disability. The administration of 17-alpha hydroxyprogesterone caproate reduces preterm birth by $33 \%$ in women with history of spontaneous preterm birth. We demonstrated previously that plasma concentrations of 17-alpha hydroxyprogesterone caproate vary widely among pregnant women and that women with 17-alpha hydroxyprogesterone caproate plasma concentrations in the lowest quartile had spontaneous preterm birth rates of $40 \%$ vs rates of $25 \%$ in those women with higher concentrations. Thus, plasma concentrations are an important factor in determining drug efficacy but the reason 17-alpha hydroxyprogesterone caproate plasma concentrations vary so much is unclear. Predominantly, 17-alpha hydroxyprogesterone caproate is metabolized by CYP3A4 and CYP3A5 enzymes.
\end{abstract}

OBJECTIVE: We sought to: (1) determine the relation between 17alpha hydroxyprogesterone caproate plasma concentrations and single nucleotide polymorphisms in CYP3A4 and CYP3A5; (2) test the association between progesterone receptor single nucleotide polymorphisms and spontaneous preterm birth; and (3) test whether the association between plasma concentrations of 17-alpha hydroxyprogesterone caproate and spontaneous preterm birth varied by progesterone receptor single nucleotide polymorphisms.

STUDY DESIGN: In this secondary analysis, we evaluated genetic polymorphism in 268 pregnant women treated with 17-alpha hydroxyprogesterone caproate, who participated in a placebo-controlled trial to evaluate the benefit of omega-3 supplementation in women with history of spontaneous preterm birth. Trough plasma concentrations of 17-alpha hydroxyprogesterone caproate were measured between 25-28 weeks of gestation after a minimum of 5 injections of 17-alpha hydroxyprogesterone caproate. We extracted DNA from maternal blood samples and genotyped the samples using TaqMan (Applied Biosystems, Foster City, $\mathrm{CA}$ ) single nucleotide polymorphism genotyping assays for the following single nucleotide polymorphisms: CYP3A4*1B, CYP3A4*1G, CYP3A4*22, and CYP3A5*3; and rs578029, rs471767, rs666553, rs503362, and rs500760 for progesterone receptor. We adjusted for prepregnancy body mass index, race, and treatment group in a multivariable analysis. Differences in the plasma concentrations of 17-alpha hydroxyprogesterone caproate by genotype were evaluated for each CYP single nucleotide polymorphism using general linear models. The association between progesterone receptor single nucleotide polymorphisms and frequency of spontaneous preterm birth was tested using logistic regression. A logistic model also tested interaction between 17-alpha hydroxyprogesterone caproate concentrations with each progesterone receptor single nucleotide polymorphism for the outcome of spontaneous preterm birth.

RESULTS: The association between CYP single nucleotide polymorphisms ${ }^{*} 22,{ }^{*} 1 \mathrm{G},{ }^{*} 1 \mathrm{~B}$, and ${ }^{*} 3$ and trough plasma concentrations of 17-alpha hydroxyprogesterone caproate was not statistically significant $(P=.68, .44, .08$, and .44 , respectively). In an adjusted logistic regression model, progesterone receptor single nucleotide polymorphisms rs578029, rs471767, rs666553, rs503362, and rs500760 were not associated with the frequency of spontaneous preterm birth $(P=.29, .10$, $.76, .09$, and .43 , respectively). Low trough plasma concentrations of 17-alpha hydroxyprogesterone caproate were statistically associated with a higher frequency of spontaneous preterm birth (odds ratio, 0.78; 95\% confidence ratio, $0.61-0.99 ; P=.04$ for trend across quartiles), however no significant interaction with the progesterone receptor single nucleotide polymorphisms rs578029, rs471767, rs666553, rs503362, and rs500760 was observed $(P=.13, .08, .10, .08$, and .13 , respectively). CONCLUSION: The frequency of recurrent spontaneous preterm birth appears to be associated with trough 17-alpha hydroxyprogesterone caproate plasma concentrations. However, the wide variation in trough 17alpha hydroxyprogesterone caproate plasma concentrations is not attributable to polymorphisms in CYP3A4 and CYP3A5 genes. Progesterone receptor polymorphisms do not predict efficacy of 17-alpha hydroxyprogesterone caproate. The limitations of this secondary analysis include that we had a relative small sample size $(n=268)$ and race was self-reported by the patients.

Key words: CYP3A4, CYP3A5 and progesterone receptor, prematurity, single nucleotide polymorphisms, spontaneous preterm birth, 17-alpha hydroxyprogesterone caproate 


\section{Introduction}

The best single predictor of spontaneous preterm birth (SPTB) is a history of SPTB. ${ }^{1}$ The administration of 17 -alpha hydroxyprogesterone caproate (17 OHPC) reduces recurrent preterm birth by a third in women with singleton gestation yet an important percentage of at-risk women do not benefit from the treatment. ${ }^{2-5}$ With the current drug administration regimen applied to women with recurrent preterm birth it was estimated that 17 OHP-C therapy would prevent about 10,000 preterm births, which would impact the overall US preterm birth rate from $12.1 \%$ down to $11.8 \%{ }^{6}$

In a previous secondary analysis from the Eunice Kennedy Shriver National Institute of Child Health and Human Development Maternal-Fetal Medicine Unit (MFMU) Network omega-3 study ${ }^{7}$ we demonstrated that plasma concentrations of 17 OHP-C vary widely (3-56 $\mathrm{ng} / \mathrm{mL}$ ) among pregnant women receiving a weekly dose of $250 \mathrm{mg}$. More importantly, women with 17 OHP-C plasma concentrations in the lowest quartile had SPTB rates of $40 \%$ vs rates of $25 \%$ in those women with higher concentrations. Thus, plasma concentrations are one of the factors that determine drug efficacy, but the reason why 17 OHP-C plasma concentrations vary so much is unclear. Because 17 OHP-C is predominantly metabolized by CYP3A4 and CYP3A5 enzymes, ${ }^{8}$ it seemed plausible that polymorphisms in CYP3A4 and CYP3A5 genes may affect 17 OHP-C plasma concentrations. Single nucleotide polymorphisms (SNPs) in CYP3A genes can impact the metabolism of several medications such as cyclosporine and tacrolimus. ${ }^{9}$ The SNPs $\mathrm{CYP} 3 A 4^{\star} 22 \quad($ rs35599367) and $\mathrm{CYP} \mathrm{A}^{\star} 3$ (rs776746) are associated with decreased enzymatic activity. ${ }^{9-17}$ Conversely, CYP3A4*1G (rs2242480) increases enzymatic activity. ${ }^{18,19}$ Finally, the SNP CYP3A4*1B (rs2740574) has been associated with higher enzymatic expression in vitro, ${ }^{20}$ however in vivo studies suggest a reduced catalytic activity for this allele. ${ }^{21}$

Progesterone is crucial for the establishment and maintenance of pregnancy and has profound effects on target cells by their expression of progesterone receptors (PR). ${ }^{22,23}$ Supplementation with progesterone both vaginally and intramuscularly has proven effective in reducing preterm birth rates in various at-risk women. ${ }^{24-26}$ An understanding of the interaction of such exogenous progesterone with PR is key to determining an optimal treatment regimen that might improve efficacy of current regimens. Several publications report that maternal or fetal polymorphisms in $P R$ are associated with increased susceptibility to preterm birth. ${ }^{27-32}$ Genomic analysis of the MFMU trial of 17 OHP-C reported by Meis et $\mathrm{al}^{2}$ suggested that the clinical efficacy of 17OHP-C may be altered by $\mathrm{PR}$ gene polymorphisms rs471767, rs578029, rs503362, and rs666553. ${ }^{33}$ In that study plasma levels of 17 OHP-C were not available and therefore no statement could be made regarding the relationship between plasma 17 OHP-C concentrations and $P R$ SNPs and their relationship to efficacy. We speculated that any perceived difference in 17 OHP-C efficacy would be associated with differences in plasma concentrations due to polymorphisms in CYP3A4 and CYP3A5 and that $P R$ polymorphisms could modulate the clinical response to 17 OHP-C.

The objectives of this study were to: (1) determine the relation between 17 OHP-C plasma concentrations and SNPs in CYP3A4 and CYP3A5; (2) test the association between $P R$ SNPs and SPTB; and (3) test whether the association between plasma concentrations of 17 OHP-C and SPTB varied by PR SNPs.

\section{Materials and Methods}

This study is a secondary analysis that used blood samples obtained from women who participated in a MFMU Network randomized, double-masked, placebo-controlled trial that evaluated the benefit of omega-3 supplementation in reducing the rate of recurrent SPTB. ${ }^{34}$ All women in the parent study received 17 OHP-C and either omega-3 supplementation or placebo. Eligibility criteria are listed in detail in the previous publication. ${ }^{34}$ The trial demonstrated that omega-3 supplementation offered no benefit in reducing preterm birth. The parent study was approved by the institutional review boards of the 13 clinical centers and the data coordinating center. The current secondary analysis was approved by the institutional review board of the University of Pittsburgh. This is a secondary analysis of a clinical trial (ClinicalTrials.gov Identifier: NCT00135902).

The methods for determination of plasma concentrations of 17 OHP-C were reported previously. ${ }^{7}$ Briefly, we used high-performance liquid chromatography-mass spectrometry with a limit of detection of $1 \mathrm{ng} / \mathrm{mL}$. Blood samples were labeled with a study identification number, thus, researchers were blinded to the patient's information. Only researchers in charge of the statistical analysis had access to the key linking the study identification number with clinical and demographic data.

\section{DNA extraction and genotyping}

As a part of the original trial protocol, maternal blood samples were collected and frozen at $-80^{\circ} \mathrm{C}$ for future analysis. We extracted the DNA from whole blood samples by using the QIAamp DNA Mini Kit (Qiagen Systems, Valencia, CA) following the manufacturer's instructions. We genotyped the samples using TaqMan SNP genotyping assays (Applied Biosystems, Foster City, CA) for SNPs in CYP3A4 (rs35599367, rs2242480, rs2740574), CYP3A5 (rs776746), and $P R$ (rs578029, rs471767, rs666553, rs503362, rs500760). TaqMan Genotyper software (Applied Biosystems) was used to automatically determine sample genotypes and generate cluster plots. The SNPs are listed, along with their known function or previously published data, in Table 1.

\section{Statistical methods}

We calculated allele and genotype frequencies for each SNP. All analyses are adjusted for self-reported race as the frequency of genotypes for some SNPs show evidence of population stratification. Markers were evaluated for deviation from Hardy-Weinberg equilibrium 
TABLE 1

Single nucleotide polymorphisms of selected genes included in analysis

\begin{tabular}{|c|c|c|c|}
\hline Allele variant & Reference SNP identification no. & Substitution & Functionality \\
\hline CYP3A4*22 & rs35599367 & $\mathrm{C}>\mathrm{T}$ & Decreased enzymatic activity ${ }^{9-17}$ \\
\hline CYP3A4*1B & rs2740574 & $A>G$ & $\begin{array}{l}\text { Higher enzymatic expression in vitro, }{ }^{20} \text { however in vivo } \\
\text { studies suggest reduced catalytic activity for this } \\
\text { allele }^{21}\end{array}$ \\
\hline CYP3A4*1G & rs2242480 & $C>T$ & $\begin{array}{l}\text { Gain-in-function polymorphism that increases } \\
\text { enzymatic activity }{ }^{18,19}\end{array}$ \\
\hline CYP3A5*3 & rs776746 & $A>G$ & Decreased enzymatic activity ${ }^{9-17}$ \\
\hline PR SNP & rs578029 & $A>T$ & May affect clinical efficacy of $170 \mathrm{HP}-\mathrm{C}^{33}$ \\
\hline PR SNP & rs471767 & $A>G$ & May affect clinical efficacy of $170 \mathrm{HP}-\mathrm{C}^{33}$ \\
\hline PR SNP & rs666553 & $\mathrm{C}>\mathrm{T}$ & May affect clinical efficacy of $170 \mathrm{HP}-\mathrm{C}^{33}$ \\
\hline PR SNP & rs503362 & $\mathrm{C}>\mathrm{G}$ & May affect clinical efficacy of $170 \mathrm{HP}-\mathrm{C}^{33}$ \\
\hline PR SNP & rs500760 & $A>G$ & May affect clinical efficacy of $170 \mathrm{HP}-\mathrm{C}^{33}$ \\
\hline PR SNP & rs653752 & $\mathrm{C}>\mathrm{G}$ & May affect clinical efficacy of $170 \mathrm{HP}-\mathrm{C}^{33}$ \\
\hline
\end{tabular}

$P R$, progesterone receptor; SNP, single nucleotide polymorphism; 17 OHP-C, 17-alpha hydroxyprogesterone caproate.

Bustos et al. Association of CYP3A and PR SNPs and 17 OHP-C. Am J Obstet Gynecol 2017.

using the exact test. SNPs not in HardyWeinberg equilibrium were eliminated from the analysis since we cannot exclude that other evolutionary influences such as mate choice, mutation, selection, genetic drift, gene flow, and meiotic drive can affect the allele frequencies. All models tested the interaction between SNP and treatment group.

The patients were stratified by race into 3 groups: Caucasian, African American, and other. Using this approach some Caucasian and African American women with Hispanic ethnicity were stratified as either Caucasians or African Americans.

In previous findings from our group only prepregnancy body mass index (BMI) affected maternal 17 OHP-C concentrations. $^{35}$ Based on the data presented above we adjusted for potential confounders including BMI, race, and treatment group. The blood samples we used to calculate the trough plasma concentrations of 17 OHP-C were taken when the patients had at least 5 consecutive injections of 17 OHP-C to ensure the drug levels were in steady state. To determine if the variation in plasma concentrations of 17 OHP-C observed in the subjects could be attributed to polymorphisms in CYP3A4 and
CYP3A5, we tested trough plasma concentrations of 17 OHP-C predicted by each CYP SNP included as an additive term using general linear models. The additive genetic effect assumes that having 2 copies of the minor allele has twice the effect of having 1 copy of the minor allele. The association between PR SNPs and the frequency of SPTB was tested in logistic regression models. To assess if the clinical response to $17 \mathrm{OHP}-$ $C$ is mediated by $P R$ polymorphisms, we tested the interaction between 17 OHPC concentrations with each $P R$ SNP for the outcome of SPTB in separate logistic regression models. We report Akaike information criterion and $\mathrm{R}^{2}$ to assess the relative quality of each model.

Model fit for logistic models was assessed using Hosmer and Lemeshow goodness-of-fit statistics. Residual analysis was used to assess model fit for general linear models. The logtransform of the concentration of 17 OHP-C was used in analyses as this variable has a log-normal distribution. We also analyzed 17 OHP-C concentration in quartiles of the distribution. The Cochran-Armitage trend test was used to assess the association between quartiles of 17 OHP-C and SPTB. The cut-off values for significance tests of the genetic markers were adjusted for multiple testing after considering the correlation among SNPs using the methods of $\mathrm{Li}$ and $\mathrm{Ji}^{36}$ in 2005. A Bonferroni correction was applied by dividing 0.05 by the number of effective markers. For CYP genes there were 4 effective SNPs resulting in an adjusted $P$ value of .0125 . For PR, there were 3 effective markers resulting in an adjusted $P$ value of .0167 . Therefore, a $P$ value $<.0125$ for CYP SNPs and a value $<.0167$ for $P R$ SNPs was considered statistically significant. All other analyses used a $P$ value of .05. SAS 9.2 software (SAS Institute Inc, Cary, NC) and R software (Bell Laboratories, Murray Hill, $\mathrm{NJ}$ ) were used in the analysis.

\section{Results}

The original trial analyzed 852 women; 271 DNA samples were available, 268 of which were of adequate quality for subsequent analyses. We analyzed $10 \mathrm{SNPs}$ in CYP3A4, CYP3A5, and $P R$ from 268 women representing $31.5 \%$ of the total women in the parent study. One marker (rs653752) failed Hardy-Weinberg equilibrium and was left out of the analysis leaving 9 SNPs in the analysis. Table 2 summarizes the demographic and clinical characteristics of the study cohort. Of patients in this study, $28 \%$ 
TABLE 2

\section{Baseline characteristics of study cohort}

\begin{tabular}{lc} 
Characteristic & \\
\hline Treatment group, $\mathrm{n}(\%)$ & $137(51.1)$ \\
\hline Race, $\mathrm{n}(\%)$ & $75(28.0)$ \\
\hline $\begin{array}{l}\text { African American } \\
\text { Caucasian }\end{array}$ & $174(64.9)$ \\
\hline Other & $19(7.1)$ \\
\hline Maternal age, mean (SD), $\mathrm{y}$ & $28(5.8)$ \\
\hline Prepregnancy BMl, mean (SD), $\mathrm{kg} / \mathrm{m}^{2}$ & $26.0(6.5)$ \\
\hline No. of previous SPTB, $\mathrm{n}(\%)$ & \\
\hline 1 & $196(73.1)$ \\
\hline 2 & $63(23.5)$ \\
\hline 3 & $6(2.2)$ \\
\hline 4 & $3(1.1)$ \\
\hline Gestational age at delivery, mean (SD), wk & $37.4(2.5)$ \\
\hline Current smoker, $\mathrm{n}(\%)$ & $29(10.8)$
\end{tabular}

$B M I$, body mass index; $S P T B$, spontaneous preterm birth.

Bustos et al. Association of CYP3A and PR SNPs and 17 OHP-C. Am J Obstet Gynecol 2017.

self-identified as African American, $64.9 \%$ self-identified as Caucasian, and $7.1 \%$ self-identified as other race including Asian, Native Hawaiian, and Pacific Islander. All of these women had a documented history of at least 1 singleton preterm delivery. We used general estimating equations to test for differences in maternal age, parity, drug use, and current smoking between the subsample of patients in the current study and the omega-3 cohort. There were more smokers in the omega-3 cohort $(16 \%, \mathrm{n}=852)$ compared to the current study $(11 \%, \mathrm{n}=268)$. There were no other statistical differences between the groups.

The association between CYP SNPs ${ }^{\star} 22,{ }^{\star} 1 \mathrm{G},{ }^{\star} 1 \mathrm{~B}$, and ${ }^{\star} 3$ and trough plasma concentrations of $17 \mathrm{OHP}-\mathrm{C}$ was not statistically significant $(P=.68, .44$, .08 , and .44, respectively). Table 3 compares the plasma 17 OHP-C concentrations according to the presence of CYP3A4 and CYP3A5 SNPs. There were no significant interactions between treatment group and CYP SNP. Adjusting for the number of injections of 17 OHP-C did not alter the results of the analysis.
$P R \quad$ SNPs rs578029, rs471767, rs666553, rs503362, and rs500760 were not associated with the frequency of SPTB $(P=.29, .10, .76, .09$, and .43 , respectively). Table 4 compares the frequency of SPTB according to the 5 allelic variants of $P R$ studied. None of the interaction tests between treatment group and SNPs was statistically significant.

After adjustment for race and treatment group, the quartiles of 17 OHP-C concentration were statistically associated with SPTB (odds ratio, 0.78; 95\% confidence ratio, $0.61-0.99, P=.04$ for trend across quartiles). The data for these findings are detailed in Table 5. In an adjusted logistic regression model low trough plasma concentrations of 17 OHP-C as a continuous variable were also statistically associated with an increased risk of SPTB (odds ratio, 0.46; 95\% confidence ratio, $0.21-0.98 ; P=$ .04). The interaction between 17 OHP-C and treatment group was not statistically significant in either model.

No significant interaction between 17 OHP-C concentrations and SPTB rates with the PR SNPs rs578029, rs471767, rs666553, rs503362, and rs500760 was observed $(P=.11, .08, .10, .08$, and .13, respectively). Table 6 evaluates how well models that include 17 OHP-C concentrations, $P R$ SNPs, and 17OHP-C $\times$ PR SNP interaction terms predict SPTB. The base model of the independent variables log 17 OHP-C concentration, race, $\mathrm{BMI}$, and treatment group predicting SPTB did not reach statistical significance. No model reached statistical significance after adding each $P R$ SNP separately to the base model.

\section{Comment}

In this study we demonstrate that the wide variation in plasma concentrations of 17 OHP-C cannot be explained by polymorphisms in the drug's primary metabolizing enzymes CYP3A4 and CYP3A5. We also affirm previous findings that the efficacy of 17 OHP-C is related to the plasma concentration achieved. Given that a fixed weekly dose of $250 \mathrm{mg} 17$ OHP-C results in a wide range of plasma concentrations and that efficacy is impacted by plasma concentration, it is likely that efficacy could be improved if higher concentrations could be achieved. The cause of the wide variation in plasma concentrations is unclear but data derived from pregnant women with singleton gestation demonstrate that maternal body weight significantly impacts both clearance and volume of distribution of 17 OHP-C ${ }^{37}$ and these effects probably account for the impact of BMI on plasma 17 OHP-C concentrations. Alternative factors that may account for the variation in 17 OHP-C plasma concentrations include other polymorphisms located in promoters, enhancer or silencer regions of the genes, and drug-drug interactions, specifically commonly used medications that compete with 17 OHP-C for metabolism such as esomeprazole, nelfinavir, fluconazole, and sertraline. ${ }^{38}$ Finally, the plasma concentration of 17 OHP-C is also affected by progesterone concentrations, which are affected by gestational age and/or placental number. ${ }^{39}$ However, none of the factors above can account for the wide variation seen in plasma concentrations.

Even though the biological samples we used in this study were obtained from 
TABLE 3

Plasma concentrations of 17-alpha hydroxyprogesterone caproate according to genotype of cytochrome P450 single nucleotide polymorphisms

\begin{tabular}{|c|c|c|c|c|c|c|c|}
\hline CYP SNP & Genotype & $\mathrm{N}$ & $\begin{array}{l}\text { Genotypic } \\
\text { frequencies }\end{array}$ & $\begin{array}{l}17 \text { OHP-C ng/mL median } \\
\text { (25th-75th percentile) }\end{array}$ & Estimate $^{a}$ & SE & $P$ value \\
\hline \multirow{3}{*}{$\begin{array}{l}\text { CYP3A4*22 } \\
(\text { rs35599367) }\end{array}$} & GG & 243 & 0.931 & $9.8(8-12.4)$ & \multirow[t]{3}{*}{0.0339} & \multirow[t]{3}{*}{0.0823} & \multirow[t]{3}{*}{.68} \\
\hline & GA & 17 & 0.065 & $10.2(7.1-16.5)$ & & & \\
\hline & AA & 1 & 0.004 & $10.9(10.9-10.9)$ & & & \\
\hline \multirow{3}{*}{$\begin{array}{l}\text { CYP3A4*1G } \\
\text { (rs2242480) }\end{array}$} & CC & 128 & 0.559 & $9.9(8.2-12.3)$ & \multirow[t]{3}{*}{0.0321} & \multirow[t]{3}{*}{0.0416} & \multirow[t]{3}{*}{.44} \\
\hline & CT & 64 & 0.279 & $10.0(7.2-12.5)$ & & & \\
\hline & TT & 37 & 0.162 & $10.0(8.2-13.5)$ & & & \\
\hline \multirow{3}{*}{$\begin{array}{l}\text { CYP3A4*1B } \\
\text { (rs2740574) }\end{array}$} & TT & 184 & 0.689 & $9.9(8.4-12.4)$ & \multirow[t]{3}{*}{0.0832} & \multirow[t]{3}{*}{0.0476} & \multirow[t]{3}{*}{.08} \\
\hline & CT & 58 & 0.217 & $11.0(8.3-13.6)$ & & & \\
\hline & CC & 25 & 0.094 & $9.8(7.9-12.1)$ & & & \\
\hline \multirow{3}{*}{$\begin{array}{l}\text { CYP3A5*3 } \\
\text { (rs776746) }\end{array}$} & CC & 154 & 0.592 & $9.9(8.3-12.4)$ & \multirow[t]{3}{*}{-0.0318} & \multirow[t]{3}{*}{0.0414} & \multirow[t]{3}{*}{.44} \\
\hline & CT & 73 & 0.281 & $10.0(7.2-12.1)$ & & & \\
\hline & TT & 33 & 0.127 & $9.9(8.4-13.3)$ & & & \\
\hline
\end{tabular}

SNP, single nucleotide polymorphism; 17 OHP-C, 17-alpha hydroxyprogesterone caproate.

${ }^{a}$ Beta estimate, SE, and $P$ value from test of general linear model of genotype in additive model predicting log $170 \mathrm{HP}-\mathrm{C}$; analysis adjusted for prepregnancy body mass index, race, and treatment group.

Bustos et al. Association of CYP3A and PR SNPs and 17 OHP-C. Am J Obstet Gynecol 2017.

TABLE 4

Frequency of spontaneous preterm birth by genotype of progesterone receptor single nucleotide polymorphisms

\begin{tabular}{|c|c|c|c|c|c|c|}
\hline$P R$ SNP & Genotype & $\mathrm{N}$ & $\begin{array}{l}\text { Genotypic } \\
\text { frequencies }\end{array}$ & SPTB, n (\%) & OR $(95 \% \mathrm{Cl})^{\mathrm{a}}$ & $P$ value \\
\hline \multirow[t]{3}{*}{ rs578029 } & $A A$ & 20 & 0.073 & $5(25.0)$ & \multirow[t]{3}{*}{$0.8(0.5-1.2)$} & \multirow[t]{3}{*}{.29} \\
\hline & AT & 115 & 0.419 & $28(24.3)$ & & \\
\hline & TT & 139 & 0.507 & $43(30.9)$ & & \\
\hline \multirow[t]{3}{*}{ rs471767 } & $A A$ & 140 & 0.509 & $45(32.1)$ & \multirow[t]{3}{*}{$0.7(0.4-1.1)$} & \multirow[t]{3}{*}{.10} \\
\hline & $A G$ & 117 & 0.425 & $26(22.2)$ & & \\
\hline & GG & 18 & 0.065 & $5(27.8)$ & & \\
\hline \multirow[t]{3}{*}{ rs666553 } & CC & 190 & 0.696 & $53(27.9)$ & \multirow[t]{3}{*}{$0.9(0.5-1.6)$} & \multirow[t]{3}{*}{.76} \\
\hline & CT & 78 & 0.285 & $21(26.9)$ & & \\
\hline & TT & 5 & 0.018 & $0(0.0)$ & & \\
\hline \multirow[t]{3}{*}{ rs503362 } & CC & 14 & 0.051 & 3 (21.4) & \multirow[t]{3}{*}{$0.7(0.4-1.1)$} & \multirow[t]{3}{*}{.09} \\
\hline & CG & 108 & 0.394 & $25(23.1)$ & & \\
\hline & GG & 152 & 0.554 & $47(30.9)$ & & \\
\hline \multirow[t]{3}{*}{ rs500760 } & CC & 20 & 0.072 & $7(35.0)$ & \multirow[t]{3}{*}{$1.2(0.8-1.8)$} & \multirow[t]{3}{*}{.43} \\
\hline & CT & 119 & 0.432 & $33(27.7)$ & & \\
\hline & TT & 136 & 0.494 & $36(26.5)$ & & \\
\hline
\end{tabular}

Cl, confidence ratio; $O R$, odds ratio; $P R$, progesterone receptor; $S N P$, single nucleotide polymorphism; SPTB, spontaneous preterm birth.

${ }^{a} P R$ SNPs entered as additive term in logistic regression models adjusted for prepregnancy body mass index, race, and treatment group.

Bustos et al. Association of CYP3A and PR SNPs and 17 OHP-C. Am J Obstet Gynecol 2017. 
Frequency of spontaneous preterm birth by quartile of 17-alpha hydroxyprogesterone caproate and race

\begin{tabular}{|c|c|c|c|c|c|c|c|c|}
\hline \multirow{4}{*}{$\begin{array}{l}\text { Quartile } \\
\text { 170HP-C }\end{array}$} & \multicolumn{8}{|c|}{ Self-reported race } \\
\hline & \multicolumn{2}{|c|}{$\begin{array}{l}\text { African American } \\
\mathrm{N}=75\end{array}$} & \multicolumn{2}{|c|}{$\begin{array}{l}\text { Caucasian } \\
N=174\end{array}$} & \multicolumn{2}{|c|}{$\begin{array}{l}\text { Other } \\
\mathrm{N}=19\end{array}$} & \multicolumn{2}{|c|}{$\begin{array}{l}\text { All }^{\mathrm{a}} \\
\mathrm{N}=268\end{array}$} \\
\hline & \multicolumn{8}{|c|}{ SPTB } \\
\hline & $\overline{n^{b}}$ & $\%^{\mathrm{C}}$ & $\mathrm{n}^{\mathrm{b}}$ & $\%^{\mathrm{C}}$ & $\mathrm{n}^{\mathrm{b}}$ & $\%^{\mathrm{C}}$ & $\mathrm{n}^{\mathrm{b}}$ & $\%^{\mathrm{C}}$ \\
\hline 1 & 5 & 27.8 & 19 & 44.2 & 1 & 25 & 25 & 38.5 \\
\hline 2 & 6 & 31.6 & 12 & 27.3 & 0 & 0 & 18 & 26.5 \\
\hline 3 & 6 & 31.6 & 12 & 27.3 & 1 & 20 & 19 & 27.9 \\
\hline 4 & 3 & 15.8 & 11 & 25.6 & 0 & 0 & 14 & 20.9 \\
\hline
\end{tabular}

SPTB, spontaneous preterm birth; 17 OHP-C, 17-alpha hydroxyprogesterone caproate.

${ }^{\mathrm{a}}$ Cochran-Armitage trend test, $P=.04 ;{ }^{\mathrm{b}}$ In each quartile; ${ }^{\mathrm{c}}$ With respect to total patients in that quartile.

Bustos et al. Association of CYP3A and PR SNPs and 17 OHP-C. Am J Obstet Gynecol 2017.

women with a history of SPTB, it is very unlikely that $17 \mathrm{OHP}-\mathrm{C}$ administration in a previous pregnancy may have residual effects in the current pregnancy, considering the half-life of 17 OHP-C is $16.2 \pm 6$ days. ${ }^{35}$ On the other hand, previous studies reported an increased activity in CYP3A enzymes during pregnancy. However, CYP3A activity goes back to basal levels during the postpartum period, ${ }^{40}$ therefore it would be very unlikely that changes in CYP enzymes from an earlier pregnancy would residual effects in the current pregnancy.

The current study also found that among women receiving 17 OHP-C, polymorphisms in $P R$ (rs578029, rs471767, rs666553, rs503362, and rs500760) are not related to SPTB and that the effectiveness of 17 OHP-C is not modified by $P R$ polymorphisms even when plasma 17 OHP-C concentrations are incorporated into the analysis. These findings may be compared to a secondary analysis performed on salivary samples from the trial of Manuck et al. ${ }^{33}$ In that study, however, women were randomized to 17 OHP-C or placebo and the analysis relating $P R$ SNPs and treatment success included both placebo and 17 OHP-C groups. This difference in study design limits the comparability of the 2 studies. The limitations of this study include that we performed a secondary analysis from a study that was not designed for pharmacogenetic purposes, therefore we had a small sample size $(\mathrm{n}=268)$. In addition, we had more smokers in the omega-3 cohort compared to the current study, which could either be a selection bias or chance. Finally, race was self-reported by the patients and our analysis did not include the genotype of the baby.

In conclusion, we confirm that the frequency of recurrent SPTB is statistically related to plasma 17 OHP-C concentrations. The wide variation in 17 OHP-C concentrations with a weekly dose of $250 \mathrm{mg}$ is not attributable to polymorphisms in CYP3A4 and CYP3A5 enzymes, although we cannot exclude that our limitation of small sample size for this study may account for a type 2 error. Selected polymorphisms of the PR do not predict efficacy. Since SPTB

TABLE 6

Association between spontaneous preterm birth and 17-alpha hydroxyprogesterone caproate concentrations with progesterone receptor single nucleotide polymorphisms with measures of relative quality of each model

\begin{tabular}{lcllr}
$P R$ SNP & LR & $P$ value $^{\mathrm{a}}$ & $\mathrm{R}^{2}$ & AIC \\
\hline Base model $^{\mathrm{b}}$ & 9.07 & .11 & 0.034 & 319 \\
\hline rs578029 & 9.98 & .13 & 0.037 & 320 \\
\hline rs471767 & 11.27 & .08 & 0.042 & 318 \\
\hline rs666553 & 10.60 & .10 & 0.039 & 315 \\
\hline rs503362 & 11.26 & .08 & 0.042 & 315 \\
\hline rs500760 & 9.82 & .13 & 0.036 & 321 \\
\hline
\end{tabular}

$A I C$, Akaike information criterion; $L R$, likelihood ratio; $P R$, progesterone receptor; $S N P$, single nucleotide polymorphism.

${ }^{\mathrm{a}}$ Model $P$ values; ${ }^{\mathrm{b}}$ Model predicting spontaneous preterm birth includes log 17 -alpha hydroxyprogesterone caproate, race, body mass index, and treatment group.

Bustos et al. Association of CYP3A and PR SNPs and 17 OHP-C. Am J Obstet Gynecol 2017. 
remains a leading cause of neonatal morbidity and mortality more studies need to be done to identify the reasons for the variability in the clinical efficacy of 17 OHP-C.

\section{Acknowledgment}

The authors thank Raman Venkataramanan, $\mathrm{PhD}$, and Wenchen Zhao, MS, for scientific mentorship and technical advice; Karen Dorman, RN, MS, for protocol development and coordination between clinical research centers; and Elizabeth Thom, PhD, John M. Thorp, Jr, MD, Margaret Harper, MD, MSc, Catherine $Y$. Spong, MD, and Mark A. Klebanoff, MD, MPH, for protocol development and oversight.

\section{References}

1. Mazaki-Tovi S, Romero R, Kusanovic JP, et al. Recurrent preterm birth. Semin Perinatol 2007;31:142-58.

2. Meis PJ, Klebanoff M, Thom E, et al. Prevention of recurrent preterm delivery by 17 alpha-hydroxyprogesterone caproate. N Engl J Med 2003;348:2379-85.

3. Merlob P, Stahl B, Klinger G. 17alpha Hydroxyprogesterone caproate for prevention of recurrent spontaneous preterm birth. Reprod Toxicol 2012;33:15-9.

4. Deeks ED. 17 alpha-Hydroxyprogesterone caproate (Makena): in the prevention of preterm birth. Paediatr Drugs 2011;13:337-45.

5. Feghali M, Venkataramanan R, Caritis S. Prevention of preterm delivery with 17hydroxyprogesterone caproate: pharmacologic considerations. Semin Perinatol 2014;38:516-22.

6. Petrini JR, Callaghan WM, Klebanoff M, et al. Estimated effect of 17 alphahydroxyprogesterone caproate on preterm birth in the United States. Obstet Gynecol 2005; 105:267-72.

7. Caritis SN, Venkataramanan R, Thom E, et al. Relationship between 17-alpha hydroxyprogesterone caproate concentration and spontaneous preterm birth. Am J Obstet Gynecol 2014;210:128.e1-6.

8. Sharma S, Ou J, Strom S, et al. Identification of enzymes involved in the metabolism of 17alpha-hydroxyprogesterone caproate: an effective agent for prevention of preterm birth. Drug Metab Dispos 2008;36:1896-902.

9. Zhou SF, Liu JP, Chowbay B. Polymorphism of human cytochrome P450 enzymes and its clinical impact. Drug Metab Rev 2009;41: 89-295.

10. Wang D, Guo Y, Wrighton SA, Cooke GE, Sadee W. Intronic polymorphism in CYP3A4 affects hepatic expression and response to statin drugs. Pharmacogenomics J 2011;11:274-86.

11. Pallet N, Jannot AS, El Bahri M, et al. Kidney transplant recipients carrying the CYP3A4*22 allelic variant have reduced tacrolimus clearance and often reach supratherapeutic tacrolimus concentrations. Am J Transplant 2015;15: 800-5.
12. Elens $L$, Bouamar R, Hesselink DA, et al. A new functional CYP3A4 intron 6 polymorphism significantly affects tacrolimus pharmacokinetics in kidney transplant recipients. Clin Chem 2011;57:1574-83.

13. Elens L, van Gelder $T$, Hesselink DA, Haufroid $V$, van Schaik $R H$. CYP3A4*22: promising newly identified CYP3A4 variant allele for personalizing pharmacotherapy. Pharmacogenomics 2013;14:47-62.

14. Kuehl P, Zhang J, Lin $Y$, et al. Sequence diversity in CYP3A promoters and characterization of the genetic basis of polymorphic CYP3A5 expression. Nat Genet 2001;27: 383-91.

15. Tavira B, Coto E, Diaz-Corte C, et al. Pharmacogenetics of tacrolimus after renal transplantation: analysis of polymorphisms in genes encoding 16 drug metabolizing enzymes. Clin Chem Lab Med 2011;49:825-33.

16. Givens $R C$, Lin $Y S$, Dowling $A L$, et al. CYP3A5 genotype predicts renal CYP3A activity and blood pressure in healthy adults. J Appl Physiol 1985;2003(95):1297-300.

17. Zheng H, Webber S, Zeevi A, et al. Tacrolimus dosing in pediatric heart transplant patients is related to CYP3A5 and MDR1 gene polymorphisms. Am J Transplant 2003;3:477-83.

18. He BX, Shi L, Qiu J, et al. A functional polymorphism in the CYP3A4 gene is associated with increased risk of coronary heart disease in the Chinese Han population. Basic Clin Pharmacol Toxicol 2011;108:208-13.

19. Lane S, Al-Zubiedi S, Hatch E, et al. The population pharmacokinetics of R- and $\mathrm{S}$ warfarin: effect of genetic and clinical factors. $\mathrm{Br}$ J Clin Pharmacol 2012;73:66-76.

20. Amirimani B, Ning B, Deitz AC, Weber BL, Kadlubar FF, Rebbeck TR. Increased transcriptional activity of the CYP3A4*1B promoter variant. Environ Mol Mutagen 2003;42:299-305.

21. Wandel C, Witte JS, Hall JM, Stein CM, Wood AJ, Wilkinson GR. CYP3A activity in African American and European American men: population differences and functional effect of the CYP3A4*1B5'-promoter region polymorphism. Clin Pharmacol Ther 2000;68:82-91.

22. Szekeres-Bartho J. Progesterone-mediated immunomodulation in pregnancy: its relevance to leukocyte immunotherapy of recurrent miscarriage. Immunotherapy 2009;1:873-82.

23. Kyurkchiev D, Ivanova-Todorova E, Kyurkchiev SD. New target cells of the immunomodulatory effects of progesterone. Reprod Biomed Online 2010;21:304-11.

24. Azargoon A, Ghorbani R, Aslebahar F. Vaginal progesterone on the prevention of preterm birth and neonatal complications in high risk women: a randomized placebo-controlled double-blind study. Int J Reprod Biomed (Yazd) 2016;14:309-16.

25. Bafghi AS, Bahrami E, Sekhavat L. Comparative study of vaginal versus intramuscular progesterone in the prevention of preterm delivery: a randomized clinical trial. Electron Physician 2015;7:1301-9.
26. Elimian A, Smith $K$, Williams M, Knudtson E, Goodman JR, Escobedo MB. A randomized controlled trial of intramuscular versus vaginal progesterone for the prevention of recurrent preterm birth. Int J Gynaecol Obstet 2016;134: 169-72.

27. Langmia IM, Apalasamy YD, Omar SZ, Mohamed Z. Progesterone receptor (PGR) gene polymorphism is associated with susceptibility to preterm birth. BMC Med Genet 2015;16:63. 28. Tiwari D, Bose PD, Das $S$, Das CR, Datta R, Bose S. MTHFR (C677T) polymorphism and PR (PROGINS) mutation as genetic factors for preterm delivery, fetal death and low birth weight: a Northeast Indian population based study. Meta Gene 2015;3:31-42.

29. Mann PC, Cooper ME, Ryckman KK, et al. Polymorphisms in the fetal progesterone receptor and a calcium-activated potassium channel isoform are associated with preterm birth in an Argentinian population. J Perinatol 2013;33:336-40.

30. Manuck TA, Major HD, Varner MW, Chettier R, Nelson L, Esplin MS. Progesterone receptor genotype, family history, and spontaneous preterm birth. Obstet Gynecol 2010;115: 765-70.

31. Guoyang L, Morgan $T$, Bahtiyar MO, et al. Single nucleotide polymorphisms in the human progesterone receptor gene and spontaneous preterm birth. Reprod Sci 2008;15:147-55.

32. Ehn NL, Cooper ME, Orr K, et al. Evaluation of fetal and maternal genetic variation in the progesterone receptor gene for contributions to preterm birth. Pediatr Res 2007;62:630-5.

33. Manuck TA, Lai Y, Meis PJ, et al. Progesterone receptor polymorphisms and clinical response to 17-alpha-hydroxyprogesterone caproate. Am J Obstet Gynecol 2011;205:135. e1-9.

34. Harper M, Thom E, Klebanoff MA, et al. Omega-3 fatty acid supplementation to prevent recurrent preterm birth: a randomized controlled trial. Obstet Gynecol 2010;115:234-42.

35. Caritis SN, Sharma S, Venkataramanan R, et al. Pharmacology and placental transport of 17-hydroxyprogesterone caproate in singleton gestation. Am J Obstet Gynecol 2012;207:398. e1-8.

36. Li J, Ji L. Adjusting multiple testing in multilocus analyses using the eigenvalues of a correlation matrix. Heredity (Edinb) 2005:95:221-7. 37. Sharma S, Caritis S, Hankins G, et al. Population pharmacokinetics of 17alpha-hydroxyprogesterone caproate in singleton gestation. Br J Clin Pharmacol 2016;82:1084-93.

38. Zhao YC, Caritis S, Venkataramanan R. Effect of prescription medications on 17-alphahydroxyprogesterone caproate (17-OHPC) metabolism [abstract 14]. Oral presentation at the Society for Maternal-Fetal Medicine 32nd Annual Meeting, Dallas, TX, February 6, 2012. 39. Cuppett CD, Zhao Y, Caritis S, Zhang S, Zhao W, Venkataramanan R. Effect of endogenous steroid hormones on 17-alpha-hydroxyprogesterone caproate metabolism. Am J Obstet Gynecol 2013;208:86.e1-6. 
40. Tracy

TS,

Venkataramanan

$R$, Glover DD, Caritis SN; National Institute for Child Health and Human Development Network of Maternal-Fetal-Medicine Units. Temporal changes in drug metabolism (CYP1A2, CYP2D6 and CYP3A activity) during pregnancy. Am J Obstet Gyneco 2005;192:633-9.
Lake City, UT (Dr Varner); Columbia University, New York, NY (Wapner); Ohio State University, Columbus, OH (lams); Women and Infants Hospital, Brown University, Providence, RI (Carpenter); Northwestern University, Chicago, IL (Peachman); Case Western Reserve University-MetroHealth Medical Center, Cleveland, $\mathrm{OH}$ (Mercer); Drexel University College of Medicine, Philadelphia, PA (Sciscione); University of Alabama at Birmingham, Birmingham, AL (Rouse); University of Texas Health Science Center at Houston, Houston, TX (Ramin); George Washington University Biostatistics Center, Washington, DC (Dr Jablonski) and Eunice Kennedy Shriver National Institute of Child Health and Human Development, Bethesda, MD (Dr Reddy). Received March 3, 2017; accepted May 7, 2017.

See Appendix for a list of other members of the Eunice Kennedy Shriver National Institute of Child Health and
Human Development Maternal-Fetal Medicine Units Network.

The project described was supported by grants from the Eunice Kennedy Shriver National Institute of Child Health and Human Development (HD27860, HD27917, HD40560, HD34208, HD40485, HD21410, HD27915, HD40500, HD40512, HD40544, M01-RR000080, HD34136, HD27869, HD40545, HD36801, HD19897) and does not necessarily represent the official views of the National Institutes of Health. Dr Bustos is a Ruth Kirschstein T-32 grant recipient, number HD071859.

The authors report no conflict of interest.

Corresponding author: Steve N. Caritis, MD. carisn@ mail.magee.edu 


\section{Appendix}

In addition to the authors, other members of the Eunice Kennedy Shriver National Institute of Child Health and Human Development Maternal-Fetal Medicine Units Network are as follows: University of Pittsburgh, Pittsburgh, PA: M. Luce, M. Cotroneo, R. Venkataramanan, W. Zhao; Wake Forest University Health Sciences, Winston-Salem, NC: M. Harper, P. Meis, M. Swain, B. Scott, C. Leftwich; Wayne State University, Detroit, MI: G. Norman, D. Driscoll, C. Sudz, L. Wynn, S. Blackwell; University of North Carolina at Chapel Hill, Chapel Hill, NC: J. Thorp, K. Dorman, E. Prata, K. Hamden; University of Utah Health Sciences Center, Salt Lake City, UT: K. Anderson (University of Utah Health Sciences Center), S. Bonnemort
(McKay-Dee Hospital), D. Lund (University of Utah Health Sciences Center), J. Russell (LDS Hospital), J. Parsons (Utah Valley Regional Medical Center); Columbia University, New York, NY: S. Bousleiman, S. South, V. Carmona, H. Husami, C. Lankford, C. Perez; Ohio State University, Columbus, $\mathrm{OH}$ : F. Johnson, M. Landon, D. Cline, H. Walker; Women and Infants Hospital, Brown University, Providence, RI: D. Allard, J. Tillinghast; Northwestern University, Chicago, IL: M. Dinsmoor (NorthShore University HealthSystem), P.J. Simon, M. Huntley, C. WhitakerCarr, M. Ramos-Brinson, G. Mallett; Case Western Reserve UniversityMetroHealth Medical Center, Cleveland, OH: C. Milluzzi, J. Hunter, W. Dalton, H. Ehrenberg, B. Stetzer; Drexel University
College of Medicine, Philadelphia, PA: M. Hoffman, M. Talucci, C. Tocci, S. Wilson, M. Lake; University of Alabama at Birmingham, Birmingham, AL: W.W. Andrews, A. Northen, M. Parks, P. Blake Files; University of Texas Health Science Center at Houston, McGovern Medical School-Children's Memorial Hermann Hospital, Houston, TX: L.C. Gilstrap, B. Glenn-Cole, K. Cannon; George Washington University Biostatistics Center, Washington, DC: E. Thom, J. Zachary, R. Palugod, L. Leuchtenburg; and Eunice Kennedy Shriver National Institute of Child Health and Human Development, Bethesda, MD: C. Spong, M. Klebanoff, S. Tolivaisa. Maternal-Fetal Medicine Units Network Steering Committee Chair (University of Texas Medical Center, Galveston, TX): G. Anderson. 